\title{
La apertura a lo absoluto y el problema de Dios
}

\section{INTRODUCCIÓN}

El tema de Dios no es tan insólito que no pueda ser tratado como cualquier otro tema filosófico. Por el contrario, la importancia del problema de Dios es fundamental, debido a su especial incidencia en la existencia humana. En efecto, la posición del hombre en el Universo, el sentido de su vida, de sus afanes y de su historia, se hallan afectados por la actitud del hombre ante este problema.

Ante el problema de Dios pueden tomarse actitudes negativas, positivas y abstenciones; hay, incluso, quienes siguiendo el análisis filosófico del lenguaje, declaran a cualquier proposición sobre Dios como carente de sentido («unsinnig»), por no ser ni tautológicas ni empíricas; esta es la posición del Círculo de Viena y, en la actualidad, de A.J. Ayer, cuando afirma que la noción de una persona, cuyos atributos esenciales no son empíricos, no es ni siquiera una noción inteligible ${ }^{1}$.

Frente a esta pluralidad de posiciones, ha sido corriente por parte de la reflexión cristiana presentar las pruebas de la existencia de Dios como argumentos en sí mismos convincentes, al margen de toda relación con las actitudes vitales de los hombres.

No es el intento de estas páginas el plantear el problema de la validez de la estructura lógica de las pruebas, sino volver a reflexionar sobre su engarce con el momento prerreflexivo, espontáneo, vital; en otros términos, el engarce con la experiencia metafísica, como punto de partida de la reflexión filosófica. En el planteamiento racional del problema de Dios, se pueden destacar dos momentos fundamentales: el primero, la apertura del hombre a lo absoluto; el segundo, la determinación de lo absoluto.

\footnotetext{
1.. AYER, A.J., Language, Truth and Logic. Victor Gollancz. London 1958, pp. 114-120.
} 
El presente trabajo, partiendo de la experiencia integral del hombre, en la cual - si realmente no está mutilada - se nos da una "presencia virtual» de lo absoluto, quiere mostrar que esta presencia es la condición que posibilita el planteamiento del problema de Dios, en Maurice Blondel y en Xavier Zubiri.

El desarrollo del tema a estudiar consta de tres partes, trabadas entre sí:

1. Una delimitación de los diferentes saberes, para ver en qué ámbito de conocimiento es posible plantear el problema de Dios.

2. Análisis de las implicaciones de la experiencia metafísica, viendo si en ella viene dada una cierta apertura del hombre al ámbito de lo absoluto.

3. Los estudios concretos de M. Blondel y X. Zubiri, desde la perspectiva del problema planteado.

\section{DELIMITACIÓN DE LOS DIFERENTES SABERES}

Esta primera parte se propone deslindar los distintos campos del saber; ello tiene gran importancia de cara a encuadrar el problema de Dios en una reflexión de naturaleza metafísica, evitando posibles confusiones, entre el ámbito de problemas científicos y filosóficos.

La experiencia más común y universal de la vida humana descubre al hombre como un ser capaz de admiración ${ }^{2}$. Quiere entender el mundo en el cual está inserto; intenta, también, dominarlo, someterlo a su servicio, dando lugar, así, a la aparición de los diferentes saberes: mítico, religioso, fïlosófico, científico-positivo.

El hombre primitivo basaba su concepción de la realidad en una interpretación mítico-religiosa que partía de una consideración «sacralizada» del cosmos. Sin embargo, paulatinamente, la humanidad ha ido recuperando el campo ocupado por la mitología, siendo muy aleccionador, a este respecto, el «mito de Prometeo».

Unido al fenómeno de la "secularización del mundo», se ha dado un progresivo desarrollo de laś ciencias particulares, que van saciando, dentro de sus respectivos campos, el apetito de inteligibilidad del hombre.

Según Albert Dondeyne ${ }^{3}$, las explicaciones científicas satisfacen de manera sorprendente las siguientes exigencias fundamentales de verdad y de certeza que mueven al hombre:

2. Un magnífico análisis del proceso de la admiración y de sus diversas fases puede encontrarse en P. CEREzo GALÁN, "La admiración como origen de la filosofía», en la Rev. Convivium, n. 15-16, Enero-Diciembre, pp. 3-32, Barcelona 1963.

3. Dondeyne, A., Fe cristiana y pensamiento contemporáneo, trad. de J. Martín Velasco. Ed. Guadarrama, Madrid 1963, p. 163. 
-Exigencia, en primer lugar, de objetividad. Necesitamos un saber objetivo, que esté más allá de la mera opinión, y que llegue a las cosas tales como son realmente.

-Exigencia de universalidad. Buscamos un saber capaz de conseguir la aprobación de todos los hombres.

-Exigencia de claridad. El espíritu humano trata de ver claro en los datos de la experiencia, explicarlos, comprenderlos. Ahora bien, "comprender» significa tomar en conjunto, descubrir relaciones, reducir la diversidad de los datos a la unidad de un sistema de ideas y leyes lógicamente coherentes.

Los conocimientos científicos se basan en experiencias verificables y controlables. «En el método científico - escribe $\mathrm{C}$. Bernard- se hacen experiencias para ver y probar, para verificar y controlar. El método experimental, en cuanto método científico, descansa enteramente sobre la verificación experimental de una hipótesis científica» ${ }^{4}$.

La ciencia positiva es perfectamente autónoma en su método, investigación y desarrollo. El peligro puede estar en confundir el horizonte del saber científico con el horizonte total de todo saber humano. A este fenómeno llamaba $R$. Le Senne la «detotalisation de la totalité», refiriéndose, con esa expresión, a la operación que consiste en pasar de la consideración de un todo, en el sentido más amplio, a la consideración de este todo privado de una de sus partes, sin dejar de atribuir al todo, así mutilado, el nombre y las propiedades del todo primitivo ${ }^{5}$.

El slogan del positivismo cientista «de que no hay otra verdad u otra inteligibilidad fuera de la verdad o inteligibilidad científica», cierra toda posibilidad a las relaciones metafísicas y al estudio de sus problemas.

Aun cuando es verdad que la ciencia trata de explicar algunas preguntas del hombre, sin embargo, cuando el hombre se pregunta por la realidad total, entre la cual se encuentra el propio ser existente, y por su sentido último, se sitúa fuera del campo de las ciencias positivas. Estas preguntas radicales acerca del sentido de todo cuanto existe, incluido el hombre, hacen referencia a realidades, que no pueden ser «cosificadas» como los objetos científicos. La posición de la ciencia es, necesariamente, neutral respecto a las afirmaciones filosóficas que trascienden el ámbito de lo verificable empíricamente. El estudio del mundo, del hombre y del origen de la totalidad son objeto de otro tipo de saber: el metafísico.

La dimensión metafísica, por consiguiente, aparece cuando el hombre, no habiéndose conformado su dinamismo cognoscitivo con las respuestas

4. BernARD, C., Introduction a l'étude de la medecine experimental. Constant-Bourquin. Genève 1945, p. 409.

5. Le Senne, R., Obstacle et valeur, Aubier, Paris 1934, p. 27. 
causales inmediatas y coextensivas con los hechos observables, se pregunta por la significación radical de sí mismo, de las cosas y del Universo en su totalidad.

Según Ortega y Gasset, el físico renuncia a preguntarse por el Universo o por el origen de todo cuanto existe; pero, por el contrario, el hombre donde cada físico vive alojado no renuncia a poseer una noción completa del mundo, una idea integral del Universo. «Delicada o tosca, con nuestra anuencia o sin ella, se incorpora en el espíritu de cada cual esa fisonomía transcientífica del mundo y viene a gobernar nuestra existencia ccn más eficacia que la verdad científica» ${ }^{6}$.

Esta visión trascientífica supone que el hombre recupera el punto de vista de la integralidad de lo real, se distancia ante las cosas, para considerarlo todo como realidad y cuestionarse por su sentido, prescindiendo de su habitual consideración pragmática.

«La consideración filosófica de la realidad - afirma J.M. Isasi-va tras la implicación última que, a modo de condición de inteligibilidad plena, viene exigida por la experiencia integral de lo real» ${ }^{7}$.

De la diferencia indicada entre el saber científico y el metafísico se deriva que la noción de justificación o prueba filosófica sea muy distinta, en cuanto a su naturaleza y características, de una prueba científica. La prueba científica demuestra de modo experimental; de ahí su carácter necesitante, que constriñe a la razón y es la base de su universalidad. La prueba filosófica no prueba ni muestra en el sentido de verificaciones empíricas, pues no trata de realidades experimentables y mensurables. Por ello, sus afirmaciones, orientadas al descubrimiento de una razón suficiente del sentido de lo real, no se imponen con carácter necesitante a la razón humana. Lo cual no es señal de ausencia de razones, sino, más bien, de la naturaleza muy diversa de las mismas.

Las realidades científicas y metafísicas, al ser distintas, exigen del hombre distinto grado de asentimiento y certeza, lo cual está muy bien reflejado en la diferencia que J.H. Newman hace entre «asentimiento» e «inferencia» ${ }^{8}$.

José Gómez Caffarena ${ }^{9}$ establece en el conocimiento, que siempre es interpretativo, tres niveles de «interpretación» de la realidad: interpretación perceptual, interpretación científica e interpretación metafísica o de sentido. Por lo tanto, la meta física, a diferencia de la física que es un saber parcial y

6. Ortega y Gasset, J., ¿Qué es Filosofía? Obras, T. 7, p. 311.

7. ISASI, J.M., Aproximación de la razón humana a Dios, en Tercera Semana de Teología de la Universidad de Deusto, Bilbao 1968 p. 381.

8. Newman, J.H., El asentimiento religioso. Herder, Barcelona 1960.

9. Gomez Caffarena, J., «Metafísica Fundamental», en Revista de Occidente, Madrid 1969, pp. 423-436. 
fenoménico, aspira a cuestionar la realidad total, en una regresión hasta el origen último, de lo real.

En las páginas siguientes, queremos analizar las implicaciones de la experiencia metafísica, en la que se vislumbra una apertura espontánea del hombre a lo «absoluto», como sentido de la realidad total.

\section{IMPLICACIONES DE LA EXPERIENCIA METAFÍSICA}

En el hombre, en su relación con las cosas, descubrimos dos dimensiones complementarias: una adorante, de acercamiento fiducial al mundo; otra interrogante, que trata de desvelar el misterio de las realidades en que vive inserto.

A diferencia del animal, el hombre es un ser capaz de «admiración». La metafísica nace del asombro, entendido como actitud intelectual problematizadora de la existencia de los seres. «Nos encontramos -dice J. Gómez Caffarena- con el hecho de nuestro existir y de nuestro existir en el mundo; con el hecho, pues, del existir del mundo. Esto nos causa extrañeza. Nos sorprende, no nos es familiar en un sentido y el más profundo, aquello mismo que somos y en ỉo que estamos» ${ }^{10}$.

Aristóteles había afirmado, en la Metafísica, que «lo que en un principio movió a los hombres a hacer las primeras indagaciones filosóficas fue, como lo es hoy, la admiración" " .

Nos veníamos preguntando «cómo son las cosas», «qué utilidad» ofrecen, con intención de dominarlas intelectual y técnicamente. Hasta que un día las cosas, los entes concretos pierden sus formas y contornos y, tras esta «desencialización», descubrimos que «son» y que esta dimensión existencial es más radical que toda pregunta por el «cómo».

Esta «extrañeza» ante la existencia ha sido magistralmente descrita por Jean Paul Sartre: «Jamás había presentido, antes de estos últimos días, lo que quería decir 'existencia'. Era como los demás, como los que pasean a la orilla del mar con sus trajes de primavera. Decía como ellos: 'el mar es verde', 'aquel punto blanco es una gaviota'; pero no sentía que aquello existía, que la gaviota era una gaviota 'existente': de ordinario la existencia se oculta. Está ahí, alrededor de nosotros, en nosotros, ella es nosotros. Y, finalmente queda intocada (...). Y de golpe estaba allí clara como el día: la existencia se descubrió de improviso. Había perdido su apariencia de ofensiva categoría abstracta: era la materia misma de las cosas. Aquella raíz estaba amasada en la existencia. $\mathrm{O}$ más bien la raíz, las verjas del jardín, el césped ralo, todo se

10. Gomez Caffarena, J., op. cit., p. 260.

11. ARISTÓteles, Metafísica, I,2. Espasa-Calpe, Madrid 1960, p. 15. 
había desvanecido; la diversidad de las cosas, su individualidad sólo era una apariencia, un barniz. Ese barniz se había fundido, quedaban masas monstruosas y blandas en desorden, desnudas con una desnudez espantosa y obscena (...); la existencia no es algo que se deja pensar de lejos: es preciso que nos invada bruscamente, que se detenga sobre nosotros» ${ }^{12}$.

Pero al mismo tiempo que captamos el existir aparece, también, la contingencia radical de nuestra existencia: «Éramos — prosigue Sartre- un montón de existencias incómodas, embarazadas por nosotros mismos, no teníamos la menor razón de estar ahí, ni unos ni otros; cada uno de los existentes, confuso, vagamente inquieto se sentía «demás» con respecto a los otros... Lo esencial es la contingencia. Quiero decir que, por definición, la existencia no es la necesidad. Existir es estar ahí simplemente» ${ }^{13}$.

Descubrimos nuestra existencia como algo que no nos pertenece y que se nos escapa de las manos. Está colgada de la nada. Según Régis Jolivet ${ }^{4}$, «nosotros existimos, en efecto, pero por así decirlo sobre el borde la nada. De ahí se deriva que sin consistir por nosotros mismos, estamos como cogidos por el cuello (desde que tenemos conciencia de nuestra condición), por la «extrañeza» absoluta de la existencia. La metafísica consiste precisamente en este «por qué» que nace de la sorpresa, de decir de la manifestación de la nada y de la angustia que determina».

El hecho de que algo existe sin dar razón de sí es lo que mueve nuestro espíritu a preguntarse el «porqué» de todo y, de un modo radical, recogiendo la frase de Leibniz, por el «por qué hay algo y no más bien nada». Esta pregunta radical lleva al hombre más allá de cualquier experiencia concreta, le hace trascender toda la realidad abriéndole hacia la necesidad de una respuesta absoluta, que adecue el hecho con su razón de ser. Nuestro espíritu se abre espontáneamente a lo último, lo absoluto.

El problema fundamental que ahora se nos plantea consiste en saber si esta búsqueda de la luz última de las cosas que empuja nuestro espíritu incansablemente es una pregunta con sentido y si tiene o no una respuesta.

Las respuestas de la técnida y de las ciencias consideran el mundo como un hecho o un producto. Solamente tratan del ente, de lo que es, como apariencia o fenómeno: el hecho de ser no plantea al sabio ninguna cuestión. El mundo está ya ahí desde que el hombre se dispone a conocerlo y describirlo. «La ciencia - dice Jolivet - puede captar la génesis en el seno del mundo, pero la génesis del Todo es para ella un problema que no puede plantearse y que 146.

12. Sartre, J.P., La Naúsea. Trad. de A. Bernárdez. Losada, Buenos Aires 1953, pp. 145 -

13. SARTRE, J.P., op. cit., pp. 146 y 149-150.

14. Jolivet, R., El hombre metafísico. Trad. de L. Medrano. Casal i Vall, Andorra 1959, p. 15 . 
nunca podrá resolver. La solución, si es posible, solamente puede incumbir a una Razón capaz de trascender el Todo, es decir, a la metafísica» ${ }^{15}$.

La pregunta radical por el fundamento de la totalidad no es, pues, respondible en el nivel científico-técnico. Tiene una ambición de totalidad, que envuelve la existencia entera, la propia, la de la comunidad y la de la Historia. Llega hasta el «por qué todo» y "para qué todo».

El hecho de que el hombre se pregunte por la razón de lo real es, a mi juicio, señal de que está convencido de que lo real está traspasado por un «logos» o razón que lo hace inteligible. Por otra parte, indica la confianza que tiene de que esa razón de lo real puede ser descubierta por la inteligencia.

Según J. Manzana, «todo filósofo en cuanto intenta dar razón de lo real, vive en la convicción de la adecuación o correspondencia entre lo «real a razonar» y la razón cognoscente que debe «dar razón» de ello: entre la razón razonante y la razón razonada o lo real como razón» ${ }^{16}$.

La búsqueda de la razón suficiente de nuestra existencia-en-el-mundo es una exigencia de la «apertura» del espíritu, que por encima del nivel científico-positivo se abre a la explicación absoluta y última de lo existente, convencido de encontrar un «sentido» radical.

Ante la posible dualidad de opción sentido-absurdo, son varios los filósofos que, en nuestros días, proclaman al hombre como absurdo y su dimensión inquisitiva radical como una frustración. Sin embargo, a mi juicio, esta posición negativa es más teórica que vivencial, ya que en el plano vital mismo vemos que no nos vivimos como absurdos; vivir es ir proclamando constantemente que tenemos sentido. Esta opción de sentido, connatural al hombre, está en la base de nuestras disposiciones, expectativas, proyectos, y del dinamismo cognoscitivo del hombre, abierto a la razón última de todo.

En síntesis, podemos decir que en estas reflexiones sobre la experiencia metafísica hemos visto cómo el hombre se descubre con extrañeza como ser con las cosas, amenazado por la nada. La finitud con que la existencia se le presenta le impulsa a trascender las respuestas acotadas y parciales de las ciencias en busca de lo «último».

«Aplicado al ejercicio metafísico natural y espontáneo del hombre - dice Jolivet - el análisis descubre en su origen una aspiración, una necesidad, una exigencia que se puede caracterizar con las palabras de «infinito» y «absoluto». Colocado o lanzado a un mundo que le abruma por su inmensidad, sin satisfacerle, y delante del cual experimenta sentimientos de sorpresa, admiración e inquietud, el hombre aparece animado por una necesidad de infinito, que le empuja o lo atrae constantemente más allá de lo que ve, capta o imagi-

15. JolIVET, R., op. cit., p. 85.

16. Manzana, J., «La vida de la razón y la afirmación de Dios» en Tercera Semana de Teologia de la Universidad de Deusto, Bilbao 1969. 
na, sin término preciso. Pero en este sentido, el infinito no es tanto el término de un movimiento sin fin hacia el futuro siempre abierto, cuanto el poder de hallar como insuficiente, precaria y limitada toda realización todo valor que se nos dé» ${ }^{17}$.

Esta apertura radical a lo absoluto es el fundamento que hace posible todo ulterior planteamiento del problema de Dios. En las restantes páginas del trabajo podremos ahondar en las reflexiones realizadas, mediante el análisis del pensamiento de dos filósofos contemporáneos: Maurice Blondel y Xavier Zubiri. Es común a ambos el descubrimiento de la apertura del hombre a lo absoluto en el análisis de su existencia y de su acción.

\section{EL DINAMISMO DE LA ACCIÓN HUMANA EN MAURICE BLONDEL}

La obra filosófica de M. Blondel es un testimonio de primera fila en lo que respecta al problema que estamos estudiando sobre la apertura del hombre a lo absoluto. Su pensamiento, de difícil comprensión, ha sido criticado como intento más «apologético» que filosófico. Es recientemente cuando va adquiriendo su merecida estima este pensador que, a mi juicio, ha sido uno de los pioneros y de los autores más importantes de nuestro tiempo sobre las relaciones filosofía-cristianismo. Nuestro objetivo, al acercarnos a este autor, consiste en analizar, a grandes rasgos, su original aportación al tema que venimos tratando.

\section{Intención}

La intención de la obra de $\mathrm{M}$. Blondel ha sido elaborar una filosofía que, en su mismo movimiento autónomo, se abriera espontáneamente al cristianismo. El vínculo que quería establecer entre filosofía y cristismo, debía asegurar la autonomía de aquélla y la trascendencia de éste. Tal era el propósito de su célebre tesis «L'Action», publicada en 1893.

Para entender bien esta obra, «L'Action», es necesario situarla, previamente, en el ambiente filosófico-cultural de la época. Por una parte, tenemos el positivismo de Renan y de Taine, que rechazan toda metafísica. Por otra parte, en el campo cristiano, aparece una corriente defensora de una religión sin dogmas ni revelación, que abocará en el Modernismo.

«L'Action» ha sido una fuerte crítica contra este ambiente cultural. Trata de superar las objeciones que parten de prejuicios, que consideran lo sobrenatural como algo que está de más. Quiere mostrar cómo una filosofía, verdaderamente fiel a su propia autonomía, lejos de cerrarse sobre sí misma, está llamada a abrirse a una trascendencia.

17. Jolivet, R., op. cit., p. 17-18. 
Ante las ya mencionadas acusaciones de «apologeta», afirmará Blondel que no se trata de apologética sino de una verdadera filosofía, llevada hasta el final. Simplemente ha intentado, como filósofo y creyente, un esfuerzo filosófico para mostrar la compatibilidad entre filosofía y cristianismo.

Blondel es consciente de la dificultad que presenta lo sobrenatural cristiano para el pensamiento filosófico inmanentista de su época: «El pensamiento moderno - dice - con su celosa susceptibilidad considera la noción de inmanencia como la condición misma de la filosofía; es decir, que si entre las ideas reinantes hay un resultado al que se adhiere como a un progreso indudable, es a la idea muy justa, en el fondo, de que nada puede entrar en el hombre que no salga de él y que no corresponda, de alguna manera, a una necesidad de expansión, y que ni como hecho histórico, ni como enseñanza tradicional, ni como obligación sobreañadida desde fuera, existe para él ninguna verdad que cuente, ningún precepto admisible, que no sea, de alguna manera, autónomo y autóctono. Ahora bien, por otra parte, nada hay cristiano y católico más que lo sobrenatural; es decir, que le es imposible al hombre sacar de sí mismo aquello que, no obstante, se pretende imponer a su pensamiento y a su voluntad» ${ }^{18}$.

En el texto citado vemos cómo lo sobrenatural cristiano se opone al pensamiento filosófico inmanentista, en cuanto que no es algo encontrado o sacado de nosotros mismos, sino recibido desde una realidad trascendente; además este don gratuito se presenta como obligatorio para el destinatario en orden a su salvación: «Sin embargo - afirma- esto que parece constituir una dificultad incompatible es lo que permite precisamente el encuentro. Si las exigencias de la Revelación son fundadas, - aún no lo sabemos, es una hipótesis-, no puede decirse que nosotros estemos completamente en nosotros; y de esta exigencia, de esta insuficiencia es preciso que haya «huella» en el hombre y «eco» en la filosofía más autónoma» ${ }^{19}$.

Según $H$. Bouillard, a la obligación notificada desde el exterior ha de corresponder una necesidad íntima, una esfera esencial de la persona: «Si le es necesario al hombre -escribe $H$. Bouillard- para su salvación acoger lo sobrenatural anunciado por la predicación cristiana, es preciso que esta necesidad esté de alguna manera inscrita en el ser; y si se halla en él inscrita, el hombre que reflexiona sobre el ser del hombre, el filósofo, podrá descubrirla, manifestarla. Al hacerlo así, mostrará que el cristianismo concierne a todo hombre» ${ }^{20}$.

18. BLONDEL, M., Lettres sur les exigences de la pensée contemporaine en matière d'apologetique, reimpresas en "Les premières écrits de $M$. Blondel», Paris 1956, p. 34. La paginación mencionada en este trabajo se refiere a esta reimpresión de «Lettres».

19. Ibid., p. 36.

20. Boulllard, H., La lógica de la fe. Taurus, Madrid 1966, p. 202. 
Buscar esta huella en el hombre y este «eco» ha sido el trabajo de $\mathrm{M}$. Blondel; tal demostración la intentó mediante el estudio de la acción humana. «La lógica de la acción - afirma Bouillard - que invita al hombre a desplegar su actividad en el terreno del mundo, le invita también a abrirse al don de una vida más alta, o si se encierra en sí mismo a condenarse» ${ }^{21}$.

El estudio de la acción es muy poco habitual en su época. Supone una vuelta a lo concreto, oponiéndose a las otras tendencias filosóficas, excesivamente intelectualistas y abstractas. Toda su filosofía para afirmar la apertura del hombre a lo absoluto parte del análisis de la acción humana.

\section{Acción e inadecuación}

¿Qué es la acción para Blondel? Por «acción» entiende aquello que abarca el movimiento total de la vida humana, es decir, las tres dimensiones fundamentales del hombre: el pensamiento, la acción y el ser del hombre. Es un error interpretar la filosofía de la acción blondeliana como una filosofía de la voluntad, propia de la psicología. «L'Action» es, por el contrario, una metafísica, una ontología.

Al estudiar las actividades del hombre, a veces, las separamos por necesidades pedagógicas, aunque en el hombre forman una estrechísima unidad. Blondel desarrolla en su Trilogía "La Pensée, L'Action y L'Être», desarrolla' distintas vías de estudio del dinamismo humano, pero estas vías hay que entenderlas como una unidad fundamental encerrada en el concepto de acción, que abarca el movimiento total del dinamismo del ser humano. La acción es el modo específico del ser del hombre como ser dinámico.

Comprobando que actuamos continuamente, que realizamos nuestra vida a través de distintas esferas de actividad, Blondel se pregunta: « $¿$ Tiene la vida humana un sentido y el hombre un destino?» ${ }^{22}$. Ésta es la pregunta capital. De la respuesta a esta pregunta depende la apertura a una posible trascendencia o la cerrazón en el absurdo.

Si existe una respuesta, ésta debe estar implicada en el dinamismo humano. Hemos de situarnos en la acción misma y ver hacia dónde apuntan sus implicaciones más profundas. Se trata de ver si en estas implicaciones hay una razón suficiente o si, por el contrario, se aboca a la negación de todo sentido. En frase de Blondel, se trata de percibir «lo que es inevitable y necesario en el despliegue total de la ación humana» ${ }^{23}$.

Al analizar el dinamismo de la acción, describe Blondel la acción humana

21. Ibid., p. 219.

22. BLONDEL, M., L'Action (1893). (Essai d'une critique de la vie et d'une science de la pratique). P.U.F. Paris 1950 , p. VII.

23. Ibid., p. 475. 
como una serie de «ondas concéntricas» a través de las cuales el hombre se va realizando como individuo, persona, ser interpersonal (familia, sociedad, humanidad).

Pero en el análisis de toda realización particular descubre Blondel una inadecuación entre la «volonté voulante» y la "volonté voulue»: «La volonté voulante ne se satisfait, ne se recouvre elle même en aucun: elle s'experimente superieure à chacun de ses termes convoités, plus ample que tous» ${ }^{24}$.

En cada una de las actividades humanas se ve una desproporción, una inadecuación entre el impulso del querer y el término de la acción, entre la «volonté voulante» y la «volonté voulue». Según J. Gómez Caffarena, «el análisis de la acción nos descubre que el hombre siempre va más allá de su objeto presente. La tendencia radical es llamada por Blondel la «volonté voulante» y la acción actual la "volonté voulue». Precisamente todo el juego del dinamismo humano es entonces para él el conato de la «volonté voulue» por adaptarse a alcanzar el anticipo que proyecta la "volonté voulante» 25 .

La inadecuación entre las dos tendencias nos testimonia vivencialmente la inexplicabilidad e insuficiencia radical del hombre en sí mismo, en cuanto circunscrito al orden natural. En el hombre hay una exigencia de expansión dinámica; está empujado a crear la familia, la sociedad, la humanidad. Sin embargo, en este orden natural no encuentra el hombre su plena satisfacción ni el descanso final de su dinamismo.

\section{Opción: el «único necesario»}

¿Cómo se puede explicar coherentemente el sentido de este dinamismo del hombre que se trasciende indefinidamente a sí mismo? El perfeccionamiento de las tendencias radicales del hombre no puede realizarse sino abriéndose a otra acción distinta a la suya que lo posibilite y lo explique. Descubrimos, así, en el dinamismo de nuestra acción la necesidad del «único necesario», punto de partida y meta final de nuestro dinamismo. Ante este ser necesario, implicado en nuestra actividad, es necesario «optar». No se trata de imposición, sino de «consentimiento». La opción es un punto fundamental en la filosofía blondeliana: o el hombre se cierra sobre sí mismo como dueño absoluto, o se entrega al orden de lo necesario, más o menos oscuramente, presente en el dinamismo de su acción.

Si el hombrè quiere bastarse sin la realidad de lo necesario, limitando su aspiración a las realidades que encuentra a su alcance, contradice el dinamismo radical de su actividad: es la muerte de la acción. Por consiguiente, la úni-

24. Ibid., p. 315.

25. Gómez Caffarena, J., op. cit., p. 198. 
ca actitud lógica que cabe al hombre es reconocer que sólo con sus fuerzas no puede alcanzar la explicación suficiente de sí mismo y de la realidad total, y que necesita abrirse a la realidad del «único necesario».

M. F. Sciacca personaliza la realidad blondeliana del «único necesario» en Dios: «El desnivel permanente-dice Sciacca - entre la «volonté voulante» y la acción realizada deja siempre insatisfecha la primera y la constriñe a ir más allá. Ninguna acción y ni siquiera la totalidad de los objetos, colman la distancia entre las dos voluntades. Solamente Dios puede llenar el abismo entre la «volonté voulante» y la «volonté voulue», entre lo que el hombre quiere ser y lo que de hecho es, entre su aspiración infinita y su pobreza actual. Nuestra sed de plenitud y de totalidad nos fuerza a llegar a ser lo que no podemos ser por nosotros mismos. En nosotros hay una deficiencia esencial, metafísicamente necesaria, y la aspiración invencible a la realidad absoluta, a Dios, inaccesible en orden a la naturaleza, se ofrece a nosotros en un orden sobrenatural» ${ }^{26}$.

Blondel llama a la realidad del «único necesario» «lo sobrenatural». Sin embargo, conviene decir que en la génesis de la idea de lo sobrenatural se dan diversas etapas. En este contexto, en el cual hemos visto el dinamismo de nuestra actividad abrirse a la realidad absoluta como principio y fin de su perfeccionamiento, no se habla, aún, de lo sobrenatural bajo una forma específicamente cristiana.

La criatura busca la comunión con Dios Creador. Pero le es imposible; depende de la iniciativa de Dios, que se hace presente en el dinamismo de la acción humana. Sin este descubrimiento de la presencia divina en nuestro dinamismo no podríamos preguntarnos por su existencia.

Según H. Bouillard, «lo que Blondel ve surgir en la dialéctica de la acción humana es la idea de un sobrenatural aún indeterminado, es decir, de lo infinito $\mathrm{y}$ de lo absoluto que todo hombre oscuramente desea, sabiendo que no puede dárselo él mismo. En una forma u otra, esa idea debe surgir en todo hombre, aún ignorante del cristianismo. Es en él la piedra angular y el punto de inserción del orden sobrenatural cristiano. Constituye, podría decirse, el «a priori» gracias al cual podrá reconocerlo y recibirlo» ${ }^{27}$.

Esta idea descubierta en todo hombre, idea de lo divino, de lo infinito, queda aún indeterminada. Requiere, por consiguiente, una determinación. En la $5 .^{\mathrm{a}}$ y última parte de $\mathrm{L}^{\prime}$ Action aparece propiamente el concepto específicamente cristiano de lo sobrenatural, considerado como lo «absolutamente imposible y absolutamente necesario al hombre» ${ }^{28}$.

26. SciacCa, M.F., La Filosofía, hoy. Trad. de Matons y de Ruiz Cuevas. Miracle, Barcelona 1956 , pp. 39-40.

27. BoulllaRD, H., op. cit., p. 215.

28. Blondel, M., L'Action (1893), p. 338. 
Blondel va a examinar si la noción cristiana de lo sobrenatural puede ser la determinación de la relación del hombre con lo absoluto. Tiene derecho, como filósofo, a confrontar la enseñanza cristiana con las aspiraciones humanas: «es legítimo - afirma Blondel- elevar la investigación hasta el punto en que sentimos que debemos desear íntimamente algo análogo a lo que desde fuera nos proponen los dogmas. Es legítimo confrontar estos dogmas con las profundas exigencias de la voluntad y descubrir en ellos la imagen de nuestras necesidades reales y la respuesta esperada. Es legítimo aceptarlas a título de hipótesis» ${ }^{29}$. «No se trata - prosigue Blondel-de reconstruir racionalmente el orden sobrenatural, ya que es ilegítimo pretender descubrir por la sola razón lo que es necesario que sea revelado para ser conocido... En esta reflexión no es necesario admitir la verdad del dogma, sino que partiendo de lo sobrenatural como hipótesis, se trata de ver si esta hipótesis se acopla ciertamente a las profundas exigencias del dinamismo de nuestra actividad inexplicable desde sí mismo. Es legítimo llevar la búsqueda filosófica hasta descubrir el «vacío» que deja el dinamismo de la acción, la necesidad de algo análogo a aquello que los dogmas nos proponen desde fuera» ${ }^{30}$.

Si en esta búsqueda vemos que la aceptación de lo sobrenatural es la condición imprescindible para el perfeccionamiento y acabamiento de la acción humana, entonces la idea de lo sobrenatural, examinada al inicio como mera hipótesis, aparecerá en adelante como una hipótesis necesaria. Blondel muestra, pues, que los diversos aspectos de la Revelación y, en consecuencia, la necesidad de la fe y de la práctica religiosa parecen llamadas por la dialéctica de la acción humana: «En efecto - afirma - hay un infinito presente en todos nuestros actos voluntarios, y a este infinito no podemos por nuestros propios medios darle cabida en nuestra reflexión, ni reproducirle por nuestro esfuerzo humano» ${ }^{31}$.

Aquí termina el cometido de la tarea de la filosofía blondeliana. La filosofía no puede abocar en lo sobrenatural como su continuación, sino que sólo es misión suya mostrar su posibilidad racional o necesidad hipotética. La religión, merced al sobrenatural, tratará de colmar el vacío dejado abierto por la filosofía. Lo sobrenatural es un don divino del todo gratuito.

La segunda noción de lo sobrenatural es una determinación de la primera. Pero el filósofo, según hemos dicho, no tiene acceso al sentido formal de la noción cristiana, más que pasando por la idea indeterminada que surge en todo hombre. «La filosofía no considera lo sobrenatural - dice Blondel- sino en tanto en cuanto su noción es inmanente a nosotros» ${ }^{32}$. La aceptación de lo

29. Blondel, M , L'Action (1893), p. 391.

30. Ibid., p. 391.

31. Ibid., p. 418.

32. Blondel, M., Lettres, pp. 86-87. 
sobrenatural no corresponde a la filosofía sino a la fe. La filosofía se detiene en los umbrales, no puede suplantar la acción divina.

\section{«Lo necesario en lo contingente»}

Como hemos dicho anteriormente, Blondel parte del análisis de la acción humana, entendiendo por tal el movimiento total de la vida, que incluye el pensamiento, la voluntad y el ser mismo del hombre. Se sirve para ello del método de la inmanencia, que consiste en «poner en ecuación, en la conciencia misma, lo que parece que pensamos, queremos y hacemos con lo que hacemos, queremos y pensamos en la realidad: de tal suerte que, en las negaciones facticias o en los fines artificialmente queridos se reencuentran de nuevo las afirmaciones profundas y las necesidades incoercibles que aquellas implican» ${ }^{33}$.

«La acción humana -escribe J.M. Isasi- en cualquiera de sus formas presenta una perfecta inadecuación entre la «volonté voulante» y la «volonté voulue». Es decir, cuantas veces la acción humana, en cualquiera de sus manifestaciones, logra llegar hasta un punto, el horizonte de esa acción y de ese dinamismo se aleja de nuevo. No hay adecuación posible dentro de la experiencia humana entre lo alcanzado, lo conseguido y ese término misterioso que de nuevo reaparece más lejos» ${ }^{34}$.

«En nuestro conocimiento, en nuestra acción - dice Blondel-, subsiste siempre una desproporción constante entre el objeto y el pensamiento, entre la obra y la voluntad. Sin cesar el ideal concebido es sobrepasa lo por la operación real, y sin cesar la realidad obtenida es sobrepasada por un ideal siempre renaciente» ${ }^{35}$.

Las exigencias de la voluntad sobrepasan, sin cesar, la insuficiencia que presenta el orden natural. Este le lleva al hombre a plantearse finalmente la cuestión de la inevitable trascendencia de la acción humana. Surge la idea de la necesidad del único necesario e inaccesible. Afirmar esta apertura del hombre a la pregunta por el significado último del dinamismo de su actividad, es lo mismo que afirmar que, de alguna forma, lo absoluto, necesario para el conocimiento ulterior de Dios, está presente en el hombre por el simple ejercicio de sus facultades humanas.

Ante esta dimensión natural de la búsqueda de la explicación última, surgida en la entraña misma de nuestra existencia dinámica, se le ofrece al hombre una alternativa ante la que es necesario optar: el hombre, o se cierra

\footnotetext{
33. Ibid., p. 39.

34. ISASI, J.M., op. cit., p. 383.

35. Blondel, M., L'Action (1893), pp. 344-345.
} 
sobre sí mismo absolutizándose o se entrega al orden divino más o menos oscuramente revelado en su conciencia. Blondel plasma este dilema fundamental, en una frase tan expresiva como sintética: «ser dios sin Dios o contra Dios, ser dios con Dios y por Dios») ${ }^{36}$.

Esta apertura del hombre a lo absoluto, es busca del sentido último o de la adecuación entre el hecho del dinamismo y su razón suficiente, es la que hace posible plantear el tema de Dios, como condición de inteligibilidad del hecho de nuestro dinamismo. Tanto el conocimiento espontáneo como el conocimiento filosófico de Dios, suponen la dimensión humana de apertura al absoluto último, fundamento de nuestra existencia y de la de las cosas.

Esta apertura del espíritu, inserta en la experiencia metafísica, es admitida tanto por metafísicos teístas como ateos: supone una opción común, la opción del sentido, de que no nos vivimos como absurdo, de que cada hecho tiene su razón suficiente que hay que buscar. Las posiciones se diversifican sobre todo a la hora de explicar ese absoluto: como un absoluto trascendente, personal y creador, o como absolutos intramundanos (humanidad, naturaleza, materia, progreso...). «Si no creéis en el Espíritu - dice F. Brunetière-, creeréis en la materia o en los espíritus por añadidura» ${ }^{37}$. El hombre no puede prescindir jamás de un absoluto y el verdadero problema se reduce a definir correctamente la naturaleza y el contenido de ese absoluto que la razón no deja de reclamar y buscar.

En resumen, no podemos acceder al descubrimiento de la existencia de algo necesario a partir de lo contingente, si eso necesario no está ya dado de alguna forma en lo contingente. «En lugar de buscar lo necesario fuera de lo contingente - dice Blondel- como un término ulterior, lo encontramos en lo contingente mismo como una realidad ya presente. En lugar de convertirlo en un soporte trascendente y exterior, descubro que es inmanente al corazón mismo de todo lo que existe. En lugar de probar simplemente la posibilidad de que lo contingente se afirme en sí sólo, se prueba la imposibilidad de negar lo necesario que lo fundamenta» ${ }^{38}$.

Ahora bien, analizando lo contingente en la actividad humana, hemos encontrado algo que le supera y le trasciende; el problema de Dios consistirá en explicitar qué es ese algo absoluto que trasciende lo contigente. En esta búsqueda de lo absoluto, corremos el riesgo de optar por absolutos relativos. La actitud del filósofo es sintetizada por san Agustín en esta humilde súplica: "Que al buscarte a ti nadie me salga al encuentro en vez de ti» ${ }^{39}$.

A continuación analizaremos algunos aspectos del pensamiento filosófico de Xavier Zubiri, en lo que respecta al tema que nos ocupa.

36. Ibid., p. 356 .

37. Brunetière, F., Discours de Combat. T. III, Paris 1908, p. 309.

38. Blondel, M., L'Action (1893), p. 343.

39. Agustin, Soliloquios, i, l.c. 1. 


\section{EL PROBLEMA DE DIOS EN X. ZUBIRI}

No es el objetivo de este trabajo realizar un estudio comparativo entre $\mathrm{M}$. Blondel y X. Zubiri. Se han tenido especialmente en cuenta estos dos filósofos por su original aportación al tema que nos ocupa, sobre la apertura de lo absoluto como condición de posibilidad del tema de Dios. Sin embargo, el planteamiento de X. Zubiri es muy similar al de Blondel: en vez del análisis de la acción, Zubiri realiza una descripción exhaustiva de la existencia humana para llegar, igualmente, a la conclusión de que su ser no se puede cerrar en su mismidad, sino que necesariamente está abocado a la trascendencia.

Queremos realizar este estudio, basándonos en el artículo de Zubiri, titulado «En torno al problema de Dios», recogido en su obra «Naturaleza, historia, Dios».

1. El problema de Dios, un pseudoproblema. El problema del mundo externo:

Zubiri inicia su trabajo sobre el tema de Dios con una referencia al problema del mundo externo. La existencia del mundo externo comienza a ser problemática desde que la orientación idealista se aparta de la realidad como dato inmediato y plantea la famosa "cuestión de puente»: ¿Cómo llegar desde una conciencia amurallada a admitir racionalmente la realidad del mundo externo? Las distintas posiciones retrotraen el problema al análisis de la subjetividad misma del sujeto: ¿es éste un ser amurallado o no?

Zubiri, recogiendo el pensamiento de una parte de la Fenomenología y Filosofía de la Existencia, define al hombre como «apertura» a las cosas: «No es que el sujeto exista - afirma Zubiri- y que además haya cosas, sino que ser sujeto consiste en estar abierto a las cosas. La exterioridad del mundo no es un simple factum sino la estructura ontológica formal del sujeto humano») ${ }^{40}$.

La existencia del mundo exterior no es algo que le adviene al hombre desde fuera sino desde sí mismo: el sí mismo no es estar encerrado en sí, sino estar abierto a las cosas; lo que el sujeto pone con esta apertura es precisamente la «apertura»y, por tanto, la «exterioridad», por lo cual es posible que haya cosas externas al sujeto y entren en él. Esta «posición» es el ser mismo del hombre. Sin cosas, pues, el hombre no sería nada ${ }^{41}$.

Por lo tanto, para Zubiri, el mundo externo lejos de ser un problema para el sujeto, es un pseudoproblema, una cuestión mal planteada, puesto que el mundo externo no es un hecho añadido, sino «un constitutivo formal y necesario del ser humano en cuanto tal» ${ }^{42}$.

40. LUBIRI, X., Naturaleza, Historia, Dios. Edit. Nacional, Madrid 1963, P. 365.

41. Ibid., p. 365 .

42. Ibid., p. 365 . 


\section{El problema de Dios:}

Ha comenzado Zubiri planteando el problema del mundo externo para mostrarnos su similitud con el problema de Dios. Muchos pensadores parten, en el problema de Dios, de que el hombre y las cosas son «substantes» y «substantivas»; de suerte que, si hay Dios, lo habrá además de estas cosas substantes. Y apelan a demostraciones racionales, al sentimiento o a la evidencia. Pero, cualquiera de estas tres posiciones suponen:

-que la «sustantividad» de las cosas exige que se demuestre que, además de ellas existe Dios;

- según esta consideración, Dios sería un «añadido» a la existencia del hombre y del mundo, y nuestro problema sería: ¿cómo llegar a él?

Frente a estas posiciones, se pregunta Zubiri: « ¿Son el sentimiento o el conocimiento, o cualquier otra facultad el «organon» para entrar en relación con Dios? ¿No será que no es asunto de ningún «organon» porque el ser mismo del hombre es constitutivamente un ser en Dios? ¿Qué sentido tiene en tal caso una demostración de la existencia de Dios?» ${ }^{43}$. Y, a continuación, Zubiri da la respuesta a su pregunta anterior: La cuestión acerca de Dios se retrotrae así a una cuestión acerca del hombre. Y la posibilidad filosófica de su conocimiento consistirá en descubrir lo que es el ser humano, para mostrarnos cómo no es necesario salir fuera de nosotros para buscar a Dios, ya que el hombre es esencialmente un ser en Dios y Dios está planteado en el hombre por el mero hecho de ser hombre ${ }^{44}$.

\section{Fenomenología de la existencia humana}

Zubiri, recogiendo el pensamiento de la Fenomenología Existencial, analiza algunos aspectos de la existencia humana, dentro de la cual la cuestión de Dios está ya planteada.

-El hombre se encuentra implantado en la existencia. Existencia (exsistere) significa el modo de ser el hombre: «sistit extra causas», está fuera de las causas que aquí son las cosas. Los demás seres «son», pero no «existen»; «exsistere» quiere decir que el hombre es un ser abierto a lo real ${ }^{45}$.

El estar implantado en la existencia conlleva para el hombre una «misión»: tener que realizarse como hombre. El realizarse del hombre existiendo es su esencia. En el Existencialismo, sabemos, la existencia precede a la esencia.

\footnotetext{
43. Ibid., p. 367

44. Ibid., p. 368-369.

45. Ibid., p. 370 .
} 
-El hombre recibe la existencia como algo «impuesto» a él. Y esto que le impone la existencia es lo que le impulsa a vivir, a hacer su ser con las cosas. Pero, el hombre para existir y realizarse como tal se encuentra apoyado «a tergo», en algo de donde le viene la vida misma ${ }^{46}$.

La vida del hombre es un don gratuito, en el sentido de que es un ser, que consiste ontológicamente en estar apoyado. Su nihilidad ontológica es radical.

-El hombre al existir con las cosas, no se encuentra sólo con cosas que hay, sino que descubre que hay que hacerse. Además de las cosas, «hay también to que hace que haya».

Zubiri nos está describiendo el ser del hombre, desde una perspectiva más ontológica que moral. Sin embargo la obligación moral depende de la religación ontológica, o, con otros términos, la moral como contenido, se apoya en la situación estructuralmente moral del hombre ${ }^{47}$.

El hombre, en el fondo de su ser, está religado a lo que hace que haya. De ahí se deriva la obligación a existir. Zubiri describe la situación del hombre como religación que nos vincula a algo que nos hace ser: «estamos obligados a existir porque previamente estamos religados a lo que nos hace existir» ${ }^{48}$.

Si algo nos hace ser, estamos religados en el nivel ontológico. Y la religación nos hace patente lo que pudiéramos llamar la «fundamentalidad» de la existencia humana, entendiendo por fundamento aquello que es raíz y apoyo a la vez.

-Pero como existir es existir con las cosas, con los otros, con el mundo, este «con» pertenece al ser mismo del hombre, no es algo añadido. Por lo tanto, si el ser del hombre es un ser religado y, además, un ser con las cosas, estas mismas cosas están religadas a su vez en el ser religado del hombre: "Lo que religa a la existencia religa con ella al mundo entero. La religación no es algo que afecta exclusivamente al hombre, a diferencia y separadamente de las cosas, sino a una con todas ellas» ${ }^{49}$.

Todas las cosas están religadas a Dios; pero sólo el hombre es un ser consciente de ello, sólo él es religioso y su ser religioso es la actualización y el reconocimiento de que su ser es un ser religado: «La existencia humana, pues, no solamente está arrojada entre las cosas, sino religada por su raíz. La religación (religión en su sentido fundamental) es una dimensión formalmente constitutiva de la existencia. Por tanto, la religación o religión no es algo que simplemente se tiene o no se tiene, el hombre no tiene religión, sino que consiste «velis nolis» en religión o religación» ${ }^{50}$.

\footnotetext{
46. Ibid., p. 371 .

47. Cfr. J.L. López Aranguren, «Ética», Revista de Occidente, Madrid 1958, pp. 63-77.

48. ZuBIRI, X., op. cit., p. .72 .

49. Ibid., p. 373.

50. Ibid., p. 373 .
} 
Por lo tanto, el problema de Dios no se le plantea al hombre desde fuera, independientemente de su ser de hombre, sino que el ser mismo del hombre se manifiesta como religado y apunta hacia lo que hace al hombre ser; y el hombre, quiera o no es religación o religión.

En estos textos se puede apreciar la actitud de Zubiri respecto al problema de Dios. En realidad es un pseudoproblema o un problema mal planteado, porque no se trata de llegar racionalmente a Dios como realidad extrínseca a nosotros. Solamente es posible plantearse el conocimiento de Dios y la justificación de su existencia, cuando se ha descubierto, previamente, que el hombre está abierto o religado a lo necesario. Aún no sabemos qué sea la realidad de lo necesario o absoluto, pero podemos afirmar que la dimensión de lo absoluto está inmersa en el ser del hombre.

«Afirmar esta apertura del hombre es lo mismo que afirmar que de alguna manera está dado lo absoluto en el hombre por el simple ejercicio de sus facultades humanas»" ${ }^{51}$.

Para Zubiri éste es el hecho más radical porque constituye el fenómeno metafísico. Si un hombre por cualquier razón que fuera no estuviera suficientemente abierto a esta radical gratuidad de la totalidad de lo existente, se hallaría en una situación semejante a la del animal. El animal ve hechos en su facticidad opaca sin preguntarse por el sentido de lo que ve; pero el hombre, por ser espíritu y por el simple ejercicio de sus facultades, está abierto a ese abismo del ser. El ser es el quehacer del espíritu humano.

El dato de que estamos implantados en el ser y de que nuestra existencia está religada a la realidad de lo "fundante» es un dato originario y previo al planteamiento del problema de Dios: «La religación no nos coloca ante la realidad precisa de un Dios, pero abre ante nosotros el ámbito de la «deidad». La deidad se nos muestra como simple correlato de la religación. En la religación estamos fundados; $y$ la deidad es «lo fundante» en cuanto tal. Lo que nos religa nos religa bajo esa forma especial que consiste en apoyarnos haciéndonos ser» ${ }^{52}$.

El descubrimiento del ámbito de la deidad, como correlato de la religación, es el principio mismo de todo ulterior conocimiento racional de Dios. La deidad es el carácter según el cual se le muestra al hombre todo lo real. Ahora bien aún no se nos dice nada acerca de qué sea la deidad como carácter último de la realidad. Lo único que sabemos es que vistas las cosas desde esta perspectiva, aparecen como reflejando ese carácter de realidad y reflejándose ellas en él. Esto es lo que constituye justamente un enigma, que fuerza a la inteligencia a un estadio ulterior: a saber qué es la deidad. La búsqueda de este

51. Ibid., p. 373.

52. Ibid., p. 375. 
«qué es la deidad» será la justificación racional o filosófica del conocimiento de Dios: «La deidad es el título de un ámbito que la razón tendrá que precisar justamente porque no sabe por simple intuición lo que es ni si tiene existencia objetiva como ente. Por su religación el hombre se ve forzado a poner en juego su inteligencia para precisar y justificar la índole de Dios como realidad. Pero la razón no lo haría si previamente la estructura ontológica de su persona, la religación, no instalara a la inteligencia por el mero hecho de existir personal y réligadamente en el ámbito de la deidad. La religación no nos coloca ante la realidad precisa de un Dios, pero abre ante nosotros el ámbito de la deidad» ${ }^{53}$.

En el análisis del descubrimiento intelectivo de Dios presenta Zubiri tres momentos progresivos: la deidad o presencia de lo absoluto, la realidad divina como causa primera de lo real, y Dios como realidad personal y libre. Cada uno de estos tres momentos se apoya en el anterior y conduce por interna necesidad al siguiente. El primero de ellos, la deidad, no es demostrativo sino simplemente mostrativo. Y es en él donde se inscriben las demostraciones de los otros momentos. En síntesis, podemos decir que, según Zubiri, previamente a todo proceso demostrativo como forma de acceso al conocimiento de Dios, es preciso que el hombre se descubra, como ser religado, abierto a este ámbito de la deidad, es decir, de la realidad fundante en cuanto tal.

\section{REFLEXIONES FINALES}

En el presente trabajo, hemos partido del hecho de nuestra existencia en el conjunto de la realidad total del universo. Ante la menesterosidad óntica de la realidad y de su problemática existencia, se vislumbra en nosotros el ámbito de lo absoluto como razón suficientemente explicativa de todo lo real. Esto lo lleva a cabo el hombre de forma espontánea. Por ello afirma Meyerson que el hombre hace metafísica como respira, sin pensar en ello.

Los análisis de Blondel y de Zubiri en los que aparece la apertura del espíritu a la realidad del «único necesario» y del «ámbito de la deidad», no son sino distintas formas de sugerir las exigencias de absoluto captadas en la pregunta del «por qué» radical explicativo de nuestra existencia y de la totalidad de lo real.

Sin tratar expresamente de buscarlas, encontramos algunas semejanzas notables entre M. Blondel y X. Zubiri:

Zubiri, partiendo del análisis de la existencia humana, juntamente con la de las cosas, la descubre «religada», es decir, abierta a la realidad de «lo fundante».

53. Ibid., p. 375 . 
Blondel parte del dinamismo del ser humano, en su triple dimensión de pensamiento, actividad y ser, y encuentra en el «único necesario» el principio y acabamiento de ese dinamismo.

Se puede apreciar la similitud existente entre el concepto blondeliano de acción, como movimiento total de la vida humana, y el concepto de existencia de Zubiri, cercano al pensamiento existencialista.

Por los análisis de ambos pensadores, vemos cómo a Dios no se le encuentra al término de una progresión racional. No es un problema a resolver, ni un dato al que queramos llegar. En opinión de G. Marcel, es un «misterio» en el que estamos envueltos.

«El problema de Dios - dice Zubiri- está ya planteado en el hombre por el mero hecho de hallarse éste implantado en la existencia. Y la misma idea aparece concisamente expresada en la siguiente frase de Blondel: «En lugar de buscar lo necesario fuera de lo contingente como un término ulterior, lo encontramos en lo contingente mismo como una realidad ya presente».

El cometido de la reflexión filosófica o prueba racional de Dios consistirá en hacer refleja esta presencia de lo absoluto - descubierta aún confusamente - en el ser mismo del hombre. La filosofía no es ruptura con la vida prerreflexiva anterior, antes al contrario, para ser fiel a sí misma ha de alimentarse de la experiencia integral humana, en la que nos descubrimos "constitutivamente religados» o desfundamentados, y abiertos, por lo tanto, a lo fundante y necesario.

La búsqueda de lo absoluto surgida en el hecho mismo de sentirnos "arrojados» a la existencia, está en la base de todas las formas de conocimiento de Dios, tanto religioso como filosófico. Así, las mismas manifestaciones religiosas de los diversos pueblos - desde la más remota antigüedad - no son sino concretizaciones de esa ansia de absoluto, captada por el hombre en mero hecho de su existir.

El conocimiento filosófico de Dios no es demostración racional de un absoluto extrínseco a nosotros, sino la explicitación racional del «por qué» radical planteado en la experiencia metafísica, al sorprendernos existiendo.

Si nos preguntamos por la existencia de ese absoluto es porque de alguna manera es realidad presente en nosotros. Según afirma Pascal, a Dios no le buscaríamos, si no le hubiéramos encontrado antes de alguna manera.

J.M. ERdozAin DE VICENTE 